\title{
Mechanisms of Cracking in Laser Welding of Magnesium Alloy AZ91D
}

\author{
Wei Zhou *(1), Aprilia Aprilia (1) and Chee Kong Mark
}

School of Mechanical and Aerospace Engineering, Nanyang Technological University, 50 Nanyang Avenue, Singapore 639798, Singapore; aprilia@ntu.edu.sg (A.A.); mark_chee_kong@moe.edu.sg (C.K.M.)

* Correspondence: mwzhou@ntu.edu.sg or wzhou@cantab.net

check for updates

Citation: Zhou, W.; Aprilia, A.; Mark, C.K. Mechanisms of Cracking in Laser Welding of Magnesium Alloy AZ91D. Metals 2021, 11, 1127. https://doi.org/10.3390/ met11071127

Academic Editors: Antonio Riveiro and Sebastian Feliú Jr.

Received: 31 May 2021

Accepted: 12 July 2021

Published: 15 July 2021

Publisher's Note: MDPI stays neutral with regard to jurisdictional claims in published maps and institutional affiliations.

Copyright: (c) 2021 by the authors. Licensee MDPI, Basel, Switzerland. This article is an open access article distributed under the terms and conditions of the Creative Commons Attribution (CC BY) license (https:// creativecommons.org/licenses/by/ $4.0 /)$.

\begin{abstract}
Considerable research has been carried out to study the laser welding of magnesium alloys. However, the studies are mainly devoted to butt welding, and there has been limited information in the published literature concerning the bead-on-plate laser welding of AZ91D, even though beadon-plate welding is required for the repair of cast AZ91D parts with surface defects. In the present investigation, surface cracking of the weld metal was observed when an AZ91D magnesium alloy was bead-on-plate welded using the laser welding method. This paper presents the experimental results and analyses to show that the cracking is "solidification cracking" initiated from the weld surface under high thermal stresses. This is in contrast to the "liquation cracking" observed in heat affected zones in tungsten inert gas welding of the same magnesium alloy. Laser power was found to be one of the main factors affecting the distance of the crack propagation. The higher laser power resulted in longer crack propagation distance into the weld metal. It is demonstrated that hot cracking could be avoided by lowering the laser power and welding speed.
\end{abstract}

Keywords: magnesium alloy; AZ91D; laser welding; hot cracking; solidification cracking

\section{Introduction}

Magnesium alloys are alloys with high specific strength and excellent recyclability. They have been increasingly used in the automobile industry and portable electronic products because of the demand for weight reduction and energy saving, as well as increasingly stringent environment regulations [1]. AZ91D is one of the most widely used magnesium alloys for casting as it possesses a good combination of mechanical properties and castability [2]. Extensive research has been conducted to optimize die casting parameters $[3,4]$ and improve mechanical properties $[5,6]$ and corrosion resistance [7-12] of AZ91D magnesium alloys.

Increasing interest has been seen, especially over the past two decades, in solving problems related to joining of various types of magnesium alloys [13-20]. Porosity [13,14] and hot cracking $[15,21]$ were identified as major problems in welding of magnesium alloys. In our previous study, hot cracking was observed in the heat affected zones (HAZ) when the bead-on-plate tungsten inert gas (TIG) welding of an AZ91D magnesium alloy was carried out [21]. High energy density welding methods such as laser beam welding $[13,14,19]$ and electron beam welding $[14,20,22]$ have been explored, and it was found that the problem of cracking is less prominent as the low net heat input produces relatively low distortion and thus less stress.

However, these studies are mainly devoted to butt welding, and there is limited information in the published literature concerning bead-on-plate laser welding of AZ91D. This is understandable because AZ91D is a magnesium alloy for casting and welding of the alloy is usually not required. However, bead-on-plate welding is required for the repair of cast AZ91D parts with surface defects. 
In this study, surface cracking was observed in the welding zone when an AZ91D magnesium alloy was bead-on-plate welded by laser. The experimental results and analyses for the cause of this cracking are presented.

\section{Experimental Procedures}

An as-cast AZ91D magnesium alloy ingot was used in this study. Table 1 shows the chemical composition of this material. The ingot was cut into thin plates of $30 \mathrm{~mm} \times$ $20 \mathrm{~mm} \times 3 \mathrm{~mm}$ using an electrical discharge wire cutting machine (EDM CNC TROOP economical model, TP-25, Troop Tech, Taipei, Taiwan) and $0.2 \mathrm{~mm}$ diameter wire with the cutting precision of $10 \mu \mathrm{m}$. A $400 \mathrm{~W}$ continuous Nd:YAG laser with $1.064 \mu \mathrm{m}$ wavelength (Lumonics JK704, GSI Lumonics, Warwickshire, England) was used to bead-weld the magnesium plates. Argon gas with a gas pressure of 3.5 bar was used as the shielding gas during the welding process. Before welding, oil and dirt were removed from the surfaces of the plates using $\mathrm{SiC}$ papers. This was done to prevent pores from forming in the welds.

Table 1. Chemical composition of the AZ91D ingot (in wt.\%).

\begin{tabular}{cccccc}
\hline $\mathbf{A l}$ & $\mathbf{M n}$ & $\mathbf{N i}$ & $\mathbf{C u}$ & $\mathbf{Z n}$ & $\mathbf{M g}$ \\
\hline 9.0 & 0.17 & 0.001 & 0.001 & 0.64 & Bal. \\
\hline
\end{tabular}

The welding was conducted using laser powers of 50 and $250 \mathrm{~W}$ with a spot size diameter of $1 \mathrm{~mm}$ at a welding speed ranging from 1 to $100 \mathrm{~mm} / \mathrm{s}$ to obtain 5 different values of heat input $(2.5,5,10,25$, and $50 \mathrm{~J} / \mathrm{mm})$. Table 2 summarizes the laser welding parameters used in this study together with the information on whether cracking was observed.

Table 2. Laser welding parameters investigated in this study.

\begin{tabular}{ccccc}
\hline No. & Power $(\mathbf{W})$ & Welding Speed $(\mathbf{m m} / \mathbf{s})$ & Heat Input $(\mathbf{J} / \mathbf{m m})$ & Cracking? \\
\hline 1 & 250 & 5 & 50 & Yes \\
\hline 2 & 250 & 10 & 25 & Yes \\
\hline 3 & 250 & 25 & 10 & Yes \\
\hline 4 & 250 & 50 & 5 & Yes \\
\hline 5 & 250 & 100 & 2.5 & Yes \\
\hline 6 & 50 & 1 & 50 & No \\
\hline 7 & 50 & 2 & 25 & No \\
\hline 8 & 50 & 5 & 10 & Yes \\
\hline 9 & 50 & 10 & 5 & Yes \\
\hline 10 & 50 & 20 & 2.5 & Yes \\
\hline
\end{tabular}

One of the bead-on-plate welds is shown in Figure 1a. Observation of the weld at higher magnification revealed cracks, as shown in Figure 1b. Cross-sections of the welded joints were etched in nital solution ( $4 \%$ nitric acid and $96 \%$ ethanol) for $5 \mathrm{~s}$, and then examined under a light optical microscope (Zeiss Axioskop 2 MAT, Carl Zeiss AG, Oberkochen, Germany) and scanning electron microscope (JOEL 5600LV SEM, JOEL, Tokyo, Japan). The SEM micrographs were obtained using the accelerating voltage of $20 \mathrm{kV}$ and the secondary electron detector. Energy dispersive X-ray spectroscopy (EDS) was used to measure the distribution of alloy elements in the samples. 


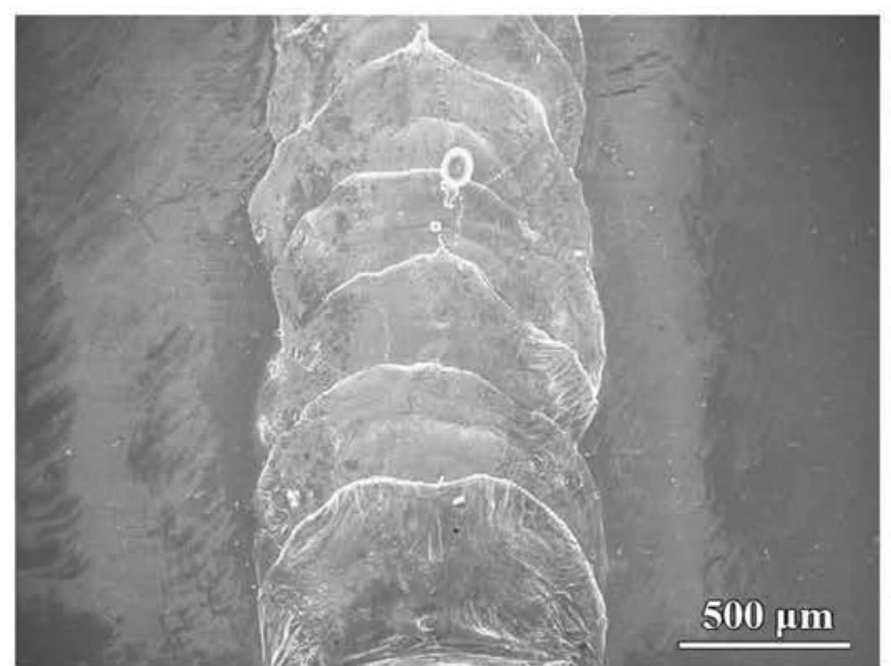

(a)

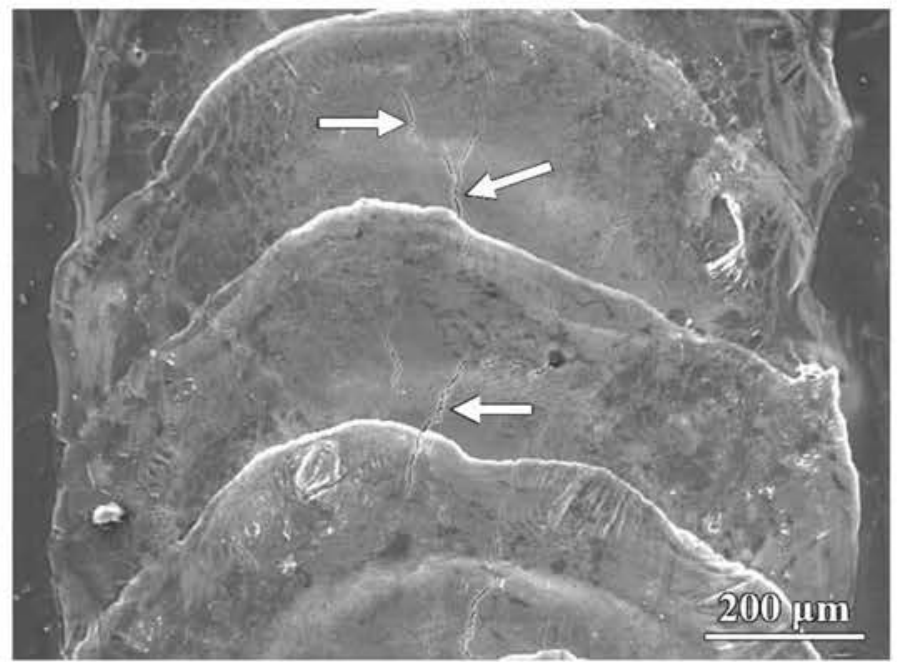

(b)

Figure 1. SEM micrographs of the bead-on-plate weld (250 W and $25 \mathrm{~mm} / \mathrm{s})$ : (a) top view; (b) close-up showing cracks on the weld surface.

\section{Results and Discussion}

\subsection{Microstructures}

Figure 2 shows the binary $\mathrm{Mg}-\mathrm{Al}$ phase diagram drawn according to the literature $[23,24]$. As shown in the diagram, the equilibrium microstructure of AZ91D alloy is made up of $\alpha-\mathrm{Mg}$ and $\beta-\mathrm{Al}_{12} \mathrm{Mg}_{17}$ intermetallics. However, the AZ91D ingot used in this study has a different microstructure due to the non-equilibrium phase transformation. As the ingot solidifies in the metal mold, the rapid cooling rate shifts the liquidus, solidus, and eutectic points in the equilibrium diagram to lower temperatures. Consequently, a segregation of the chemical composition in the form of divorced eutectic phase appeared in the matrix. Upon examination, the microstructure of the AZ91D ingot contains large primary $\alpha-\mathrm{Mg}$ dendrites and eutectic phase developed between the dendritic arms, as shown in Figure 3. The eutectic phase contains secondary $\alpha\left(\alpha^{\prime}\right)$ and $\beta-\mathrm{Al}_{12} \mathrm{Mg}_{17}$.

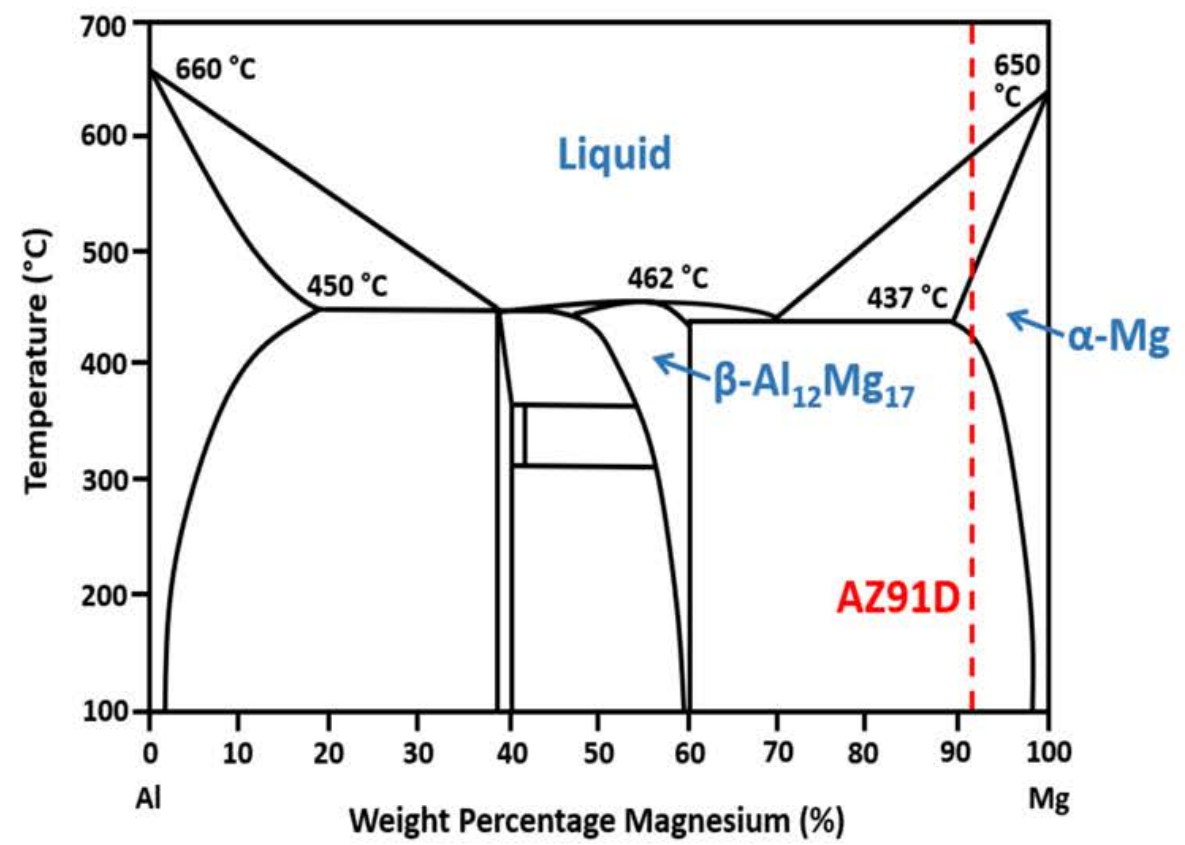

Figure 2. Binary $\mathrm{Mg}-\mathrm{Al}$ phase diagram. 


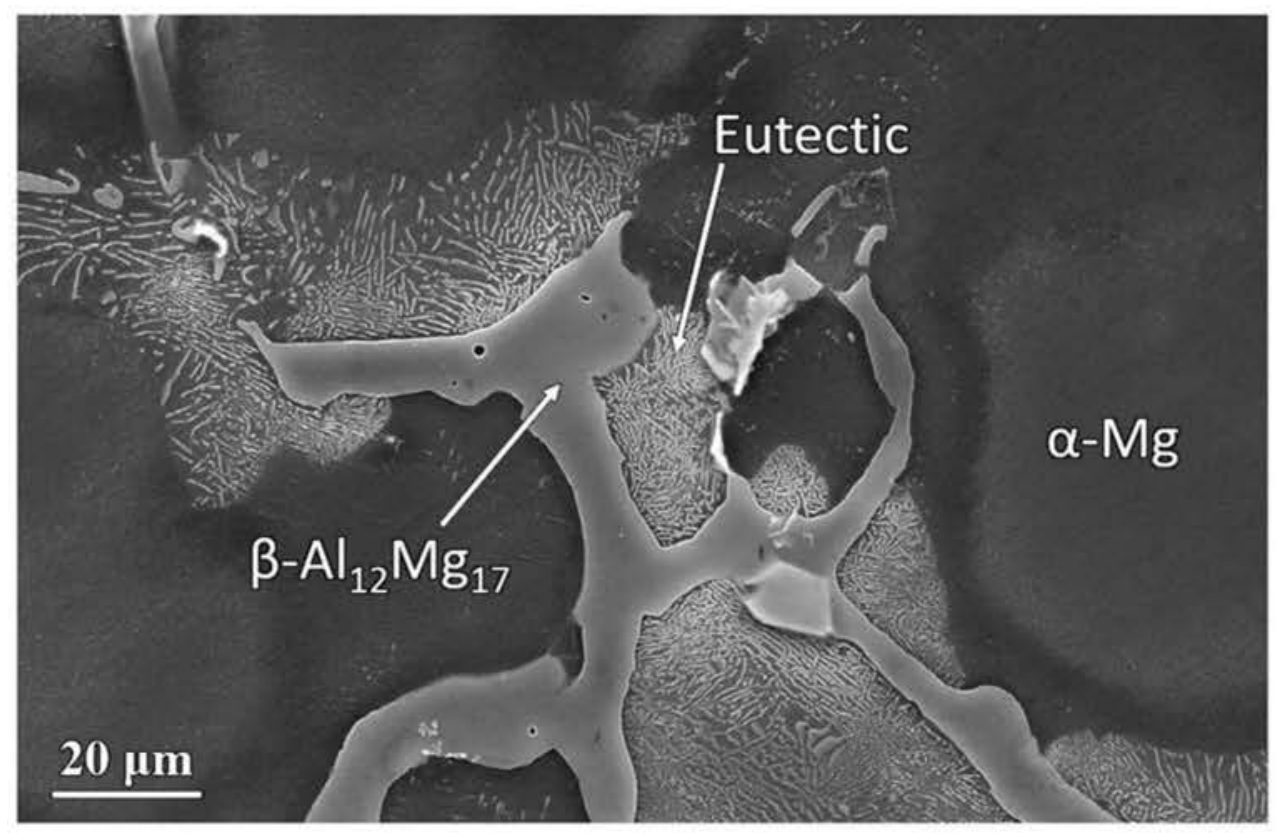

Figure 3. SEM micrograph showing microstructures of AZ91D ingot containing $\alpha-\mathrm{Mg}, \beta-\mathrm{Al}_{12} \mathrm{Mg}_{17}$ and eutectic phase.

The cross-section of the bead-on-plate weld is presented in Figure 4. The weld zone, $\mathrm{HAZ}$, and base metal are indicated in the figure. Figure 5 shows the microstructure of the weld zone at a higher magnification.

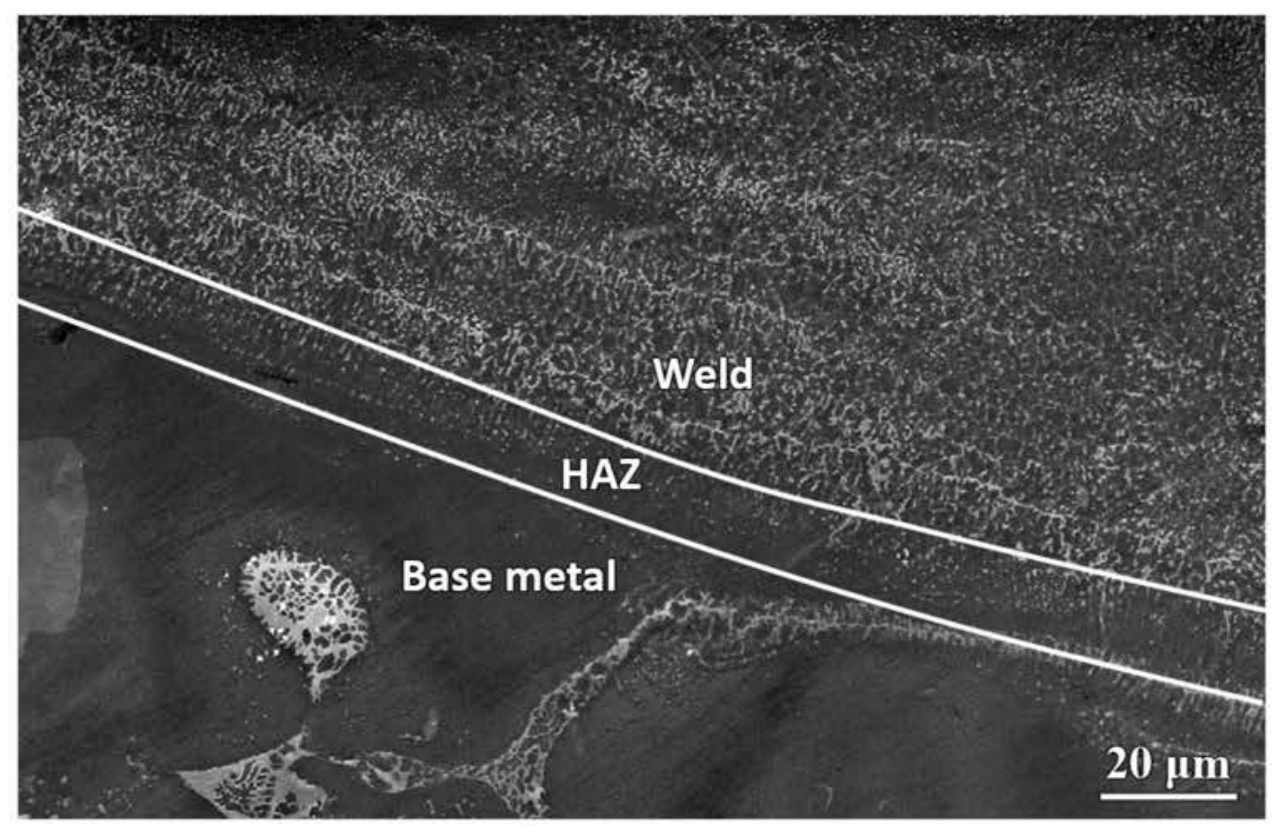

Figure 4. SEM micrograph of AZ91D showing weld metal, HAZ, and base metal (250 W, $5 \mathrm{~mm} / \mathrm{s})$. 


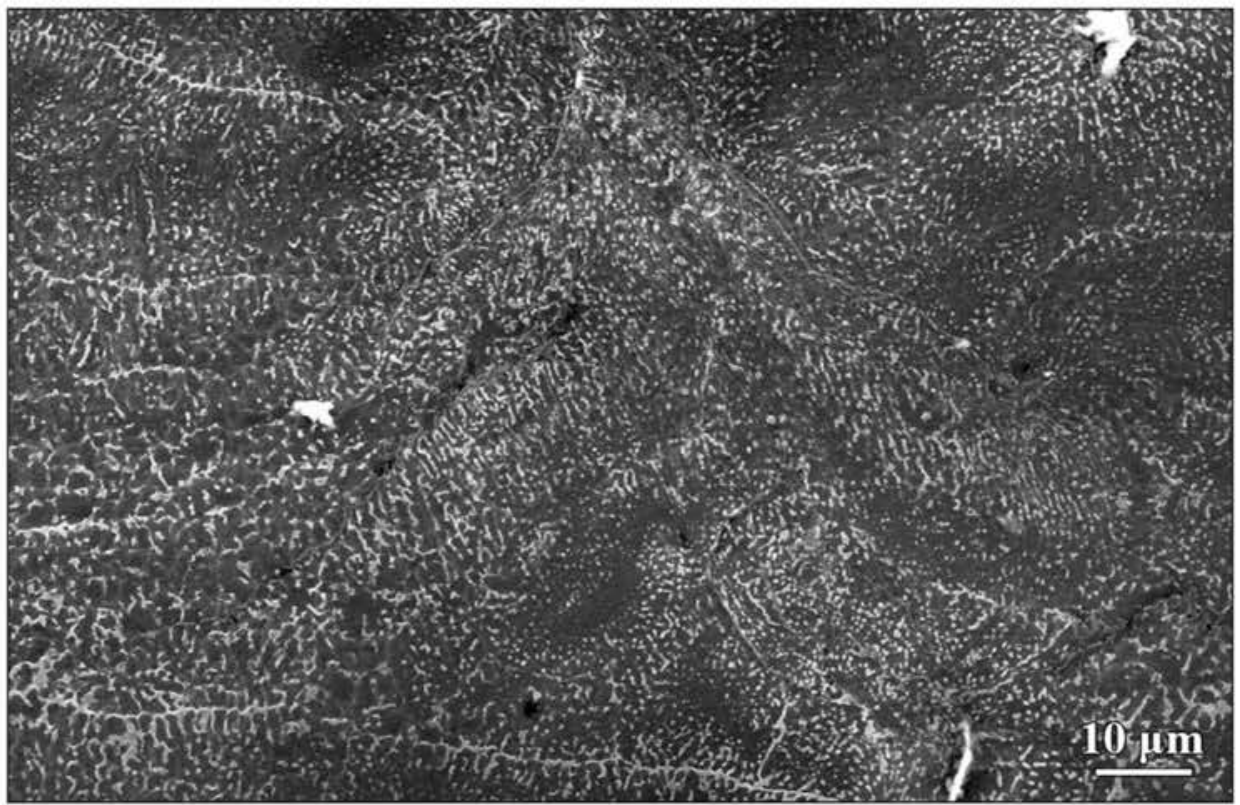

Figure 5. SEM micrograph showing microstructure of the weld zone $(250 \mathrm{~W}, 5 \mathrm{~mm} / \mathrm{s})$.

Compared with the coarse grains (about $100 \mu \mathrm{m}$ in diameter) in the parent material (as shown in Figure 3), much finer microstructures (less than $5 \mu \mathrm{m}$ ) formed in the weld metal (Figure 5). These fine grains formed due to the rapid cooling during the laser welding process.

Figure 6 shows the measured chemical composition of the weld metal analyzed by EDS. The chemical composition of the weld metal was found to differ from that of the base metal. EDS analyses show that the average aluminum content at the top weld region is the highest (11.63 wt.\%), followed by 11.37 wt.\% in the middle weld and 9.38 wt.\% in the base metal. The increasing aluminum content in the fusion zone is believed to be due to the loss of magnesium during the welding operation as magnesium has a high vapor pressure at high temperatures and thus evaporates easily at high temperatures during the laser welding process. A similar phenomenon was observed by Guan et al. [7] when studying the laser surface melting of AZ91D alloy.

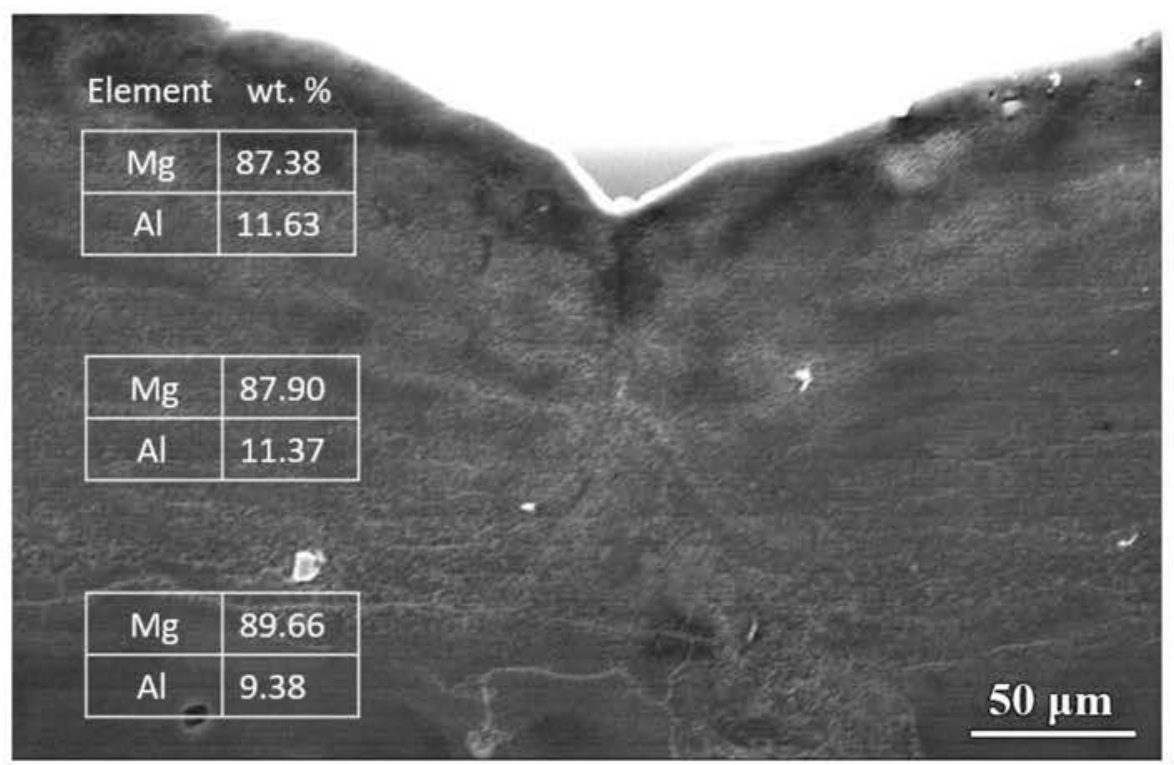

Figure 6. EDS analyses showing the different element percentages at the top weld, middle weld, and base metal $(250 \mathrm{~W}, 5 \mathrm{~mm} / \mathrm{s})$. 


\subsection{Hot Cracking in Bead-on-Plate Weld}

Centric cracking from surface was identified in the weld-bead of the AZ91D plate at a laser power of $250 \mathrm{~W}$. This cracking is categorized as hot cracking as it developed at high temperatures. It occurred quite consistently in all specimens welded with $250 \mathrm{~W}$ laser power. Figure 7 shows the appearance of the crack in the weld bead. Based on the observation of the crack profile, cracking initiated from the top surface and propagated into the weld metal (see Figure $7 b$ ).

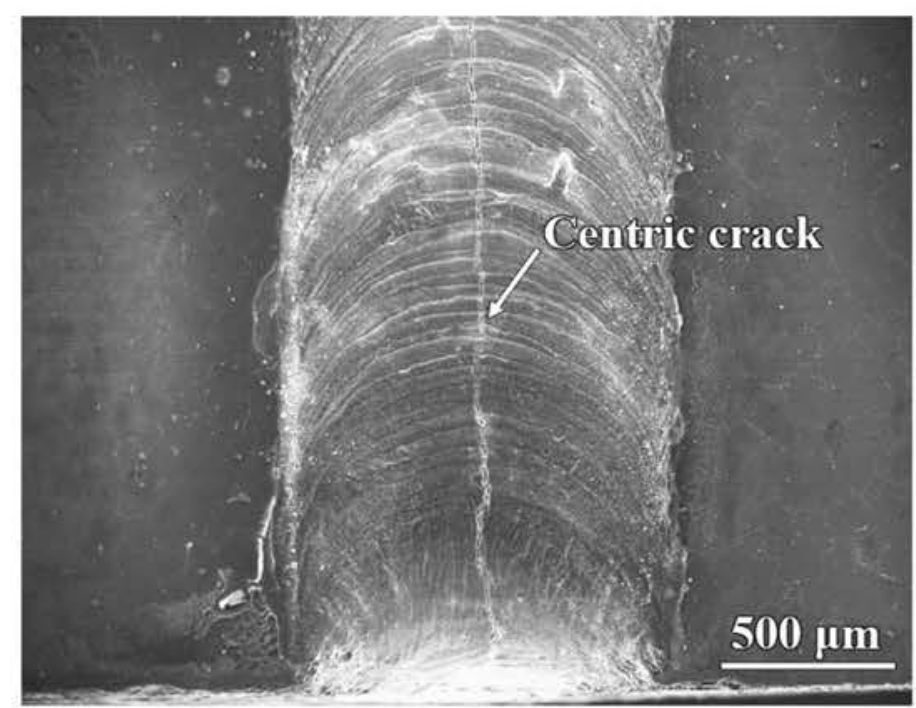

(a)

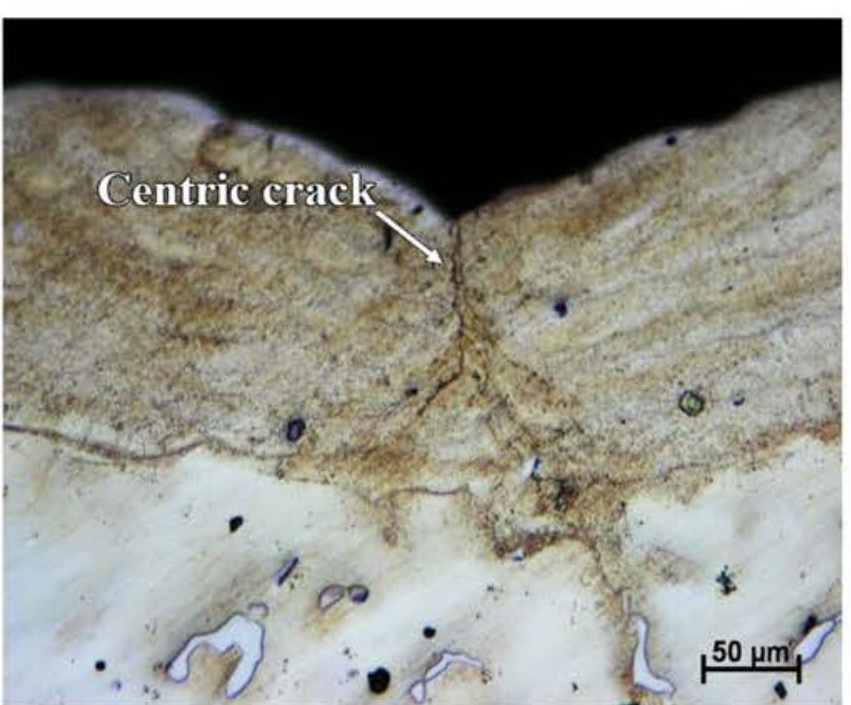

(b)

Figure 7. Centric crack in the weld bead ( $250 \mathrm{~W}, 5 \mathrm{~mm} / \mathrm{s})$ : (a) SEM micrograph showing the top view; (b) optical micrograph showing the cross-sectional view.

Classical theories on hot cracking's mechanisms were developed by Borland [25] and Prokhorov [26]. Hot cracking can generally be categorized into two types: solidification cracking in the weld and liquation cracking in the HAZ. The former, according to Provkhorov's theory [26], occurs in the BTR (brittle temperature range) during the weld metal solidification. In the brittle temperature range, the strength of the weld is greatly decreased by the liquid film existing between the grains. When the thermal strain or strain rate during the welding process exceeds the material's endurance, "solidification cracking" will occur in the weld.

For liquation cracking, it relates to the liquation of low melting point precipitates or the second phase in the matrix. This type of cracking may take place in the HAZ when subjected to tensile stresses if the low melting point microstructures in the zone partially melt at high temperatures during welding. In our previous study of TIG welding of magnesium alloy AZ91D, hot cracking was found to be liquation cracking from the HAZ [21]. In contrast, the hot cracking observed in this study is likely to be of solidification cracking type as it was observed to initiate from the top surface of the weld and propagate into the weld metal. The two different scenarios of hot cracking in the same material (AZ91D) are compared schematically in Figure 8.

As the metallurgical factor and the mechanical factor are usually the two main factors that cause crack formation, metallographic evaluation and stress analysis were carried out in this study to further understand the hot cracking phenomenon.

For metallographic observation, after grinding, polishing, and etching, the samples that were segmented out from the cracked weld were observed under SEM. Attention was directed to the center of the weld bead as the hot cracking was observed to initiate from there. As shown in Figure 9, the hot crack was observed to propagate along the eutectic phase. Along the hot crack path, a high volume of eutectic phase can be seen. However, 
the hot crack path was found to be arrested inside the weld and did not propagate into the

HAZ. The HAZ was found to be free of crack, as shown in Figure 10.

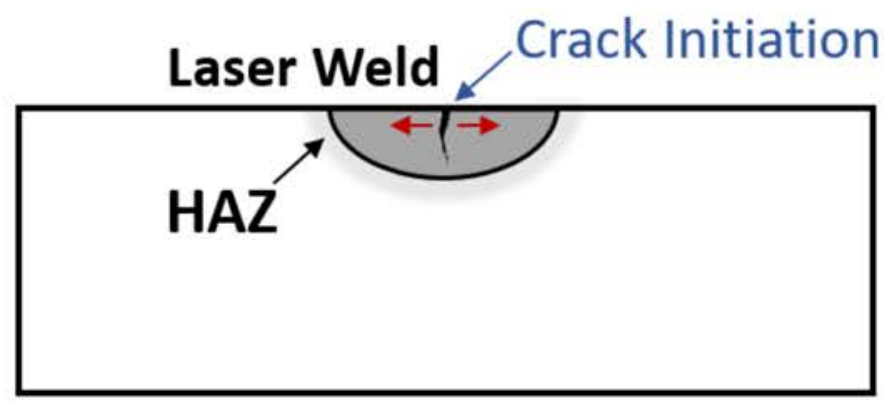

(a)
TIG Weld

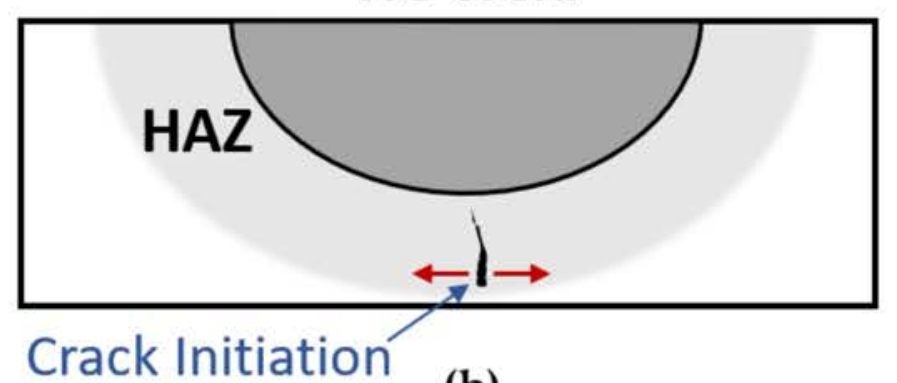

(b)

Figure 8. Illustration of two different scenarios of hot cracking in bead-on-plate welding of magnesium alloy AZ91D: (a) solidification cracking initiated at the weld surface during laser welding; (b) liquation cracking initiated in HAZ during TIG welding [21].

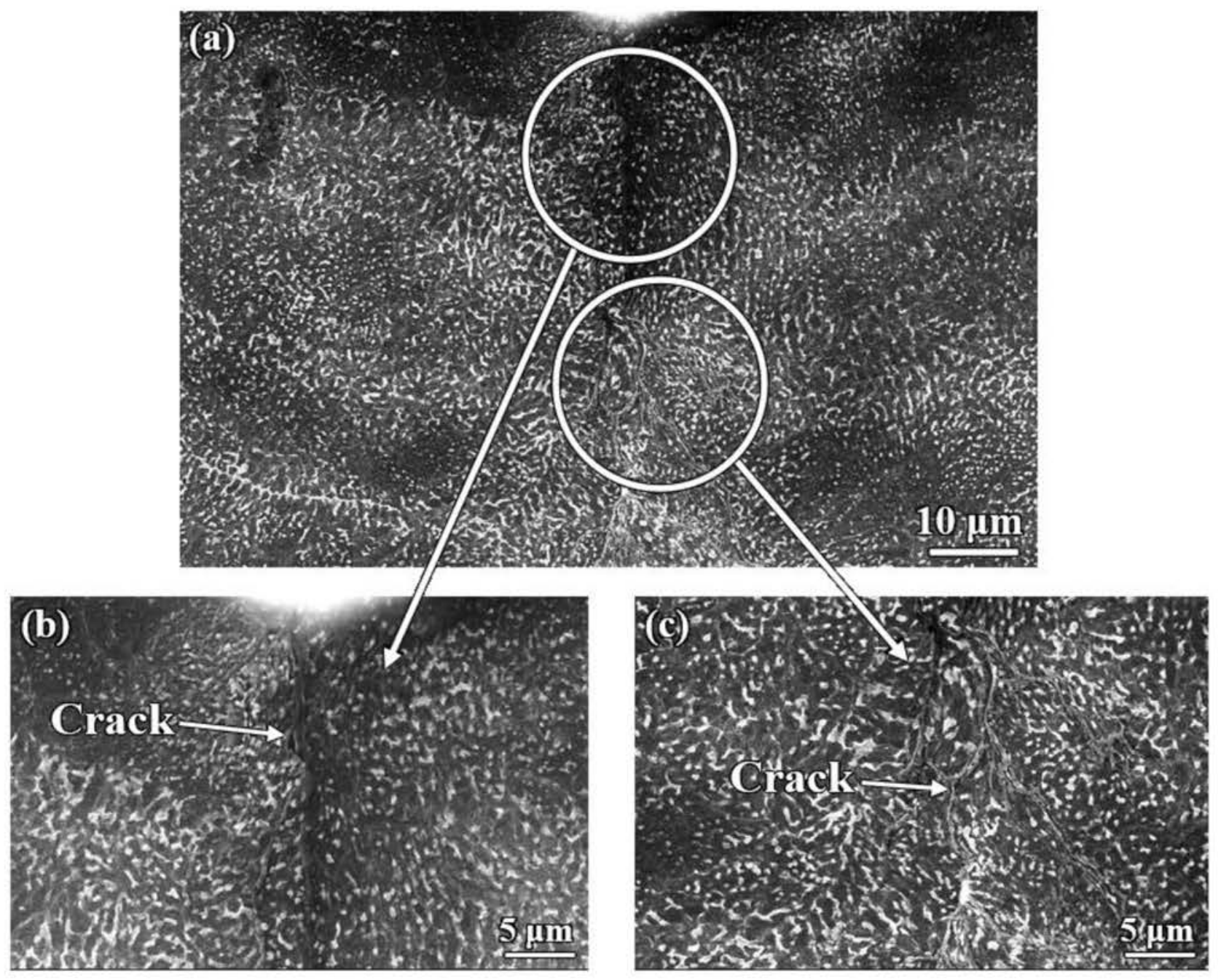

Figure 9. Hot crack propagates along the eutectic phase in the weld (250 W, $5 \mathrm{~mm} / \mathrm{s})$ : (a) SEM micrograph showing overall weld zone; (b) top region of the weld zone; (c) bottom region of the weld zone. 


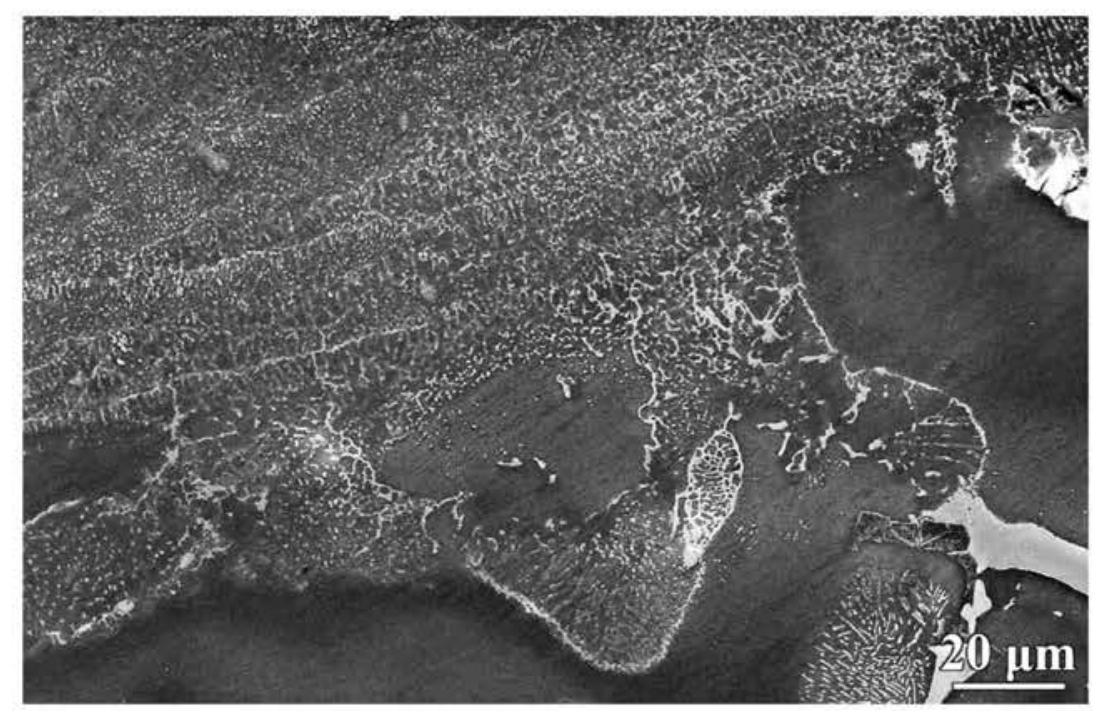

Figure 10. SEM image showing crack-free HAZ (250 W, $5 \mathrm{~mm} / \mathrm{s})$.

As discussed above and shown in Figure 6, laser welding resulted in enrichment of $\mathrm{Al}$ content in the weld metal (especially in the top layer of the weld metal). This led to an increase in the amounts of brittle $\beta-\mathrm{Al}_{12} \mathrm{Mg}_{17}$ intermetallics, contributing to the hot cracking in the weld metal.

Cracking was also observed in the weld-bead with the lower laser welding power of $50 \mathrm{~W}$ for the welding speeds of 5,10 , and $20 \mathrm{~mm} / \mathrm{s}$. The major difference lies in that the propagation depth is shorter than the crack path with the higher laser welding power of $250 \mathrm{~W}$, as shown in Figure 11. Although the reduced laser power decreases the cracking, the weld penetration became shallower as well. From the comparison, it can be summarized that solidification cracking occurs with both laser welding powers of 250 and $50 \mathrm{~W}$, and the laser power is one of the main factors affecting the distance of the crack propagation.

In terms of the mechanical factor, magnesium alloys have a low specific heat capacity $\left(1025 \mathrm{Jkg}^{-1} \mathrm{~K}^{-1}\right.$ at $\left.20^{\circ} \mathrm{C}\right)$ and high thermal conductivity $\left(156 \mathrm{Wm}^{-1} \mathrm{~K}^{-1}\right.$ at $\left.27^{\circ} \mathrm{C}\right)$ [27]. When laser irradiates the sample, the sample's surface rapidly heats up and cools down, resulting in high thermal stresses. As the melting and solidification occur within a very short interaction time and remain confined only to the top surface, the lower layer acts as a heat sink without any noticeable change in microstructure [19]. Therefore, the thermal stress is higher at the surface of the weld-bead, and the weld tends to solidify within a short interval. It can be concluded that the cracking is solidification cracking, which initiates from the top surface of the weld due to higher thermal stress at the surface.

It is important to note that thermal stresses are higher for the bead-on-plate repair of cast AZ91D parts than for butt welding. In butt welding, the two plates may move freely during thermal contraction of the weld metal; however, during bead-on-plate welding repair, when the molten metal solidifies and then contracts, the subjacent base metal poses a rigid constraint and thus leads to high tensile thermal stresses in the weld metal. 


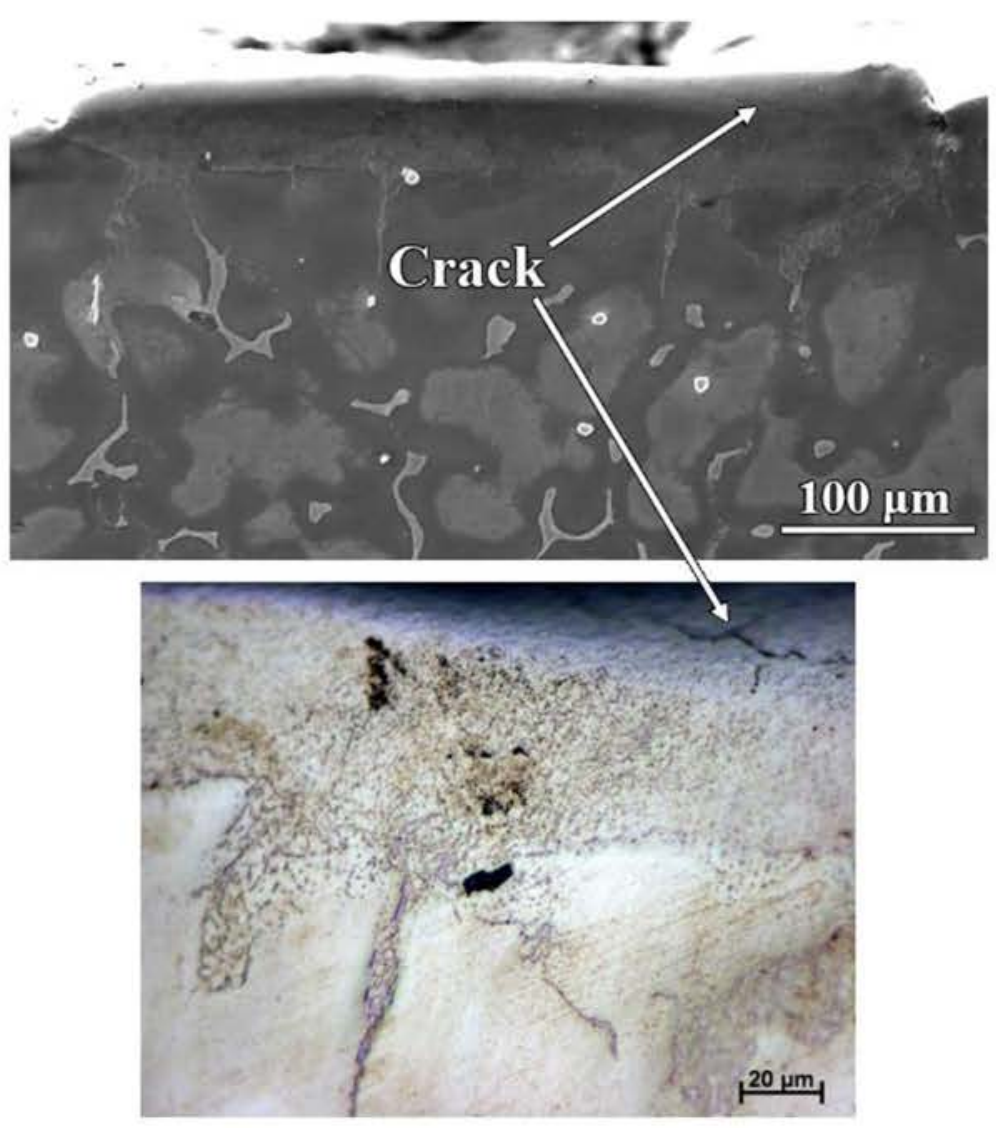

Figure 11. Hot crack in the bead-on-plate welded AZ91D with laser welding power of $50 \mathrm{~W}$ at welding speed of $10 \mathrm{~mm} / \mathrm{s}$.

Effort was made to obtain crack-free weld beads. In the case of lower laser power of $50 \mathrm{~W}$, cracking occurred when the welding speed was 5, 10, and $20 \mathrm{~mm} / \mathrm{s}$, but it disappeared when the welding speed was reduced to 1 and $2 \mathrm{~mm} / \mathrm{s}$ (Table 2). Reducing the speed leads to higher heat input, which slows down the cooling process and therefore helps to reduce the thermal stresses. The heat input for obtaining the crack-free weld bead for $50 \mathrm{~W}$ laser power was calculated to be 25 and $50 \mathrm{~J} / \mathrm{mm}$ (Table 2). However, cracking still occurred at the same heat input of 25 and $50 \mathrm{~J} / \mathrm{mm}$ for the higher laser power of $250 \mathrm{~W}$. This is perhaps due to the higher heating rate for the higher laser power. An even higher heat input might be required to obtain a crack-free weld bead. However, when the heat input is very high, there is the risk of avoiding solidification cracking in the weld bead at the expense of causing liquation cracking in the HAZ [21], as illustrated in Figure 8. Therefore, a feasible way to avoid cracking in the weld bead is to use low laser power and low welding speed.

Recently, Zhang et al. [28] comprehensively reviewed the effect of laser pulse shaping on the microstructure and hot cracking behavior in the welding of a large variety of alloys. Their review focuses on the usual butt welding instead of bead-on-plate welding repair. However, the method of managing heat input through the use of pulsed laser may be explored for the purpose of avoiding hot cracking in bead-on-plate welding of magnesium alloy AZ91D.

\section{Conclusions}

Hot cracking was observed to propagate from the surface of the weld bead into the weld metal during bead-on-plate laser welding of an AZ91D magnesium alloy. The cracking was found to be "solidification cracking" initiated from the surface under the high thermal stresses. The laser power was found to be one of the main factors affecting the distance of the crack propagation. The higher laser power resulted in longer crack 
propagation distance into the weld metal. Welding speed was also found to affect the occurrence of cracking. A higher welding speed will result in higher thermal stresses to the weld. Hot cracking can be avoided by using a lower laser power and lower welding speed.

Author Contributions: Conceptualization, W.Z.; methodology, W.Z.; validation, A.A.; formal analysis and investigation, A.A. and C.K.M.; data curation, A.A. and C.K.M.; writing-original draft preparation, W.Z. and A.A.; writing-review and editing, W.Z.; visualization, A.A.; supervision, W.Z.; project administration, W.Z.; funding acquisition, W.Z. All authors have read and agreed to the published version of the manuscript.

Funding: This research was funded by Majestic Rock Resources Group Pte. Ltd. through award \#020866-00001.

Acknowledgments: The authors would like to thank the School of Mechanical and Aerospace Engineering, Nanyang Technological University for the research support.

Conflicts of Interest: The authors declare no conflict of interest.

\section{References}

1. Xu, Y.; Yang, Y.; Peng, X.; Song, J.; Pan, F. Overview of advancement and development trend on magnesium alloy. J. Magnes. Alloys 2019, 7, 536-544. [CrossRef]

2. Aung, N.N.; Zhou, W.; Lim, L.E. Wear behaviour of AZ91D alloy at low sliding speeds. Wear 2008, 265, 780-786. [CrossRef]

3. Li, Y.B.; Zhou, W. Numerical simulation of filling process in die casting. Mater. Technol. 2003, 18, 36-41. [CrossRef]

4. Huang, Y.J.; Hu, B.H.; Pinwill, I.; Zhou, W.; Taplin, D.M.R. Effects of process settings on the porosity levels of AM60B magnesium die "“castings. Mater. Manuf. Process. 2000, 15, 97-105. [CrossRef]

5. Bag, A.; Zhou, W. Tensile and fatigue behavior of AZ91D magnesium alloy. J. Mater. Sci. Lett. 2001, 20, 457-459. [CrossRef]

6. Puga, H.; Carneiro, V.; Barbosa, J.; Vieira, V. Effect of ultrasonic treatment in the static and dynamic mechanical behavior of AZ91D Mg alloy. Metals 2015, 5, 2210-2221. [CrossRef]

7. Guan, Y.C.; Zhou, W.; Zheng, H.Y. Effect of laser surface melting on corrosion behaviour of AZ91D Mg alloy in simulated-modified body fluid. J. Appl. Electrochem. 2009, 39, 1457-1464. [CrossRef]

8. Ma, A.; Lu, F.; Zhou, Q.; Jiang, J.; Song, D.; Chen, J.; Zheng, Y. Formation and corrosion resistance of micro-arc oxidation coating on equal-channel angular pressed AZ91D Mg alloy. Metals 2016, 6, 308. [CrossRef]

9. Ambat, R.; Aung, N.N.; Zhou, W. Evaluation of microstructural effects on corrosion behaviour of AZ91D magnesium alloy. Corros. Sci. 2000, 42, 1433-1455. [CrossRef]

10. Wu, G.; Fan, Y.; Gao, H.; Zhai, C.; Zhu, Y.P. The effect of Ca and rare earth elements on the microstructure, mechanical properties and corrosion behavior of AZ91D. Mater. Sci. Eng. A 2005, 408, 255-263. [CrossRef]

11. Zhou, W.; Shen, T.; Aung, N.N. Effect of heat treatment on corrosion behaviour of magnesium alloy AZ91D in simulated body fluid. Corros. Sci. 2010, 52, 1035-1041. [CrossRef]

12. Aung, N.N.; Zhou, W. Effect of heat treatment on corrosion and electrochemical behaviour of AZ91D magnesium alloy. J. Appl. Electrochem. 2002, 32, 1397-1401. [CrossRef]

13. Weisheit, A.; Galun, R.; Mordike, B.L. $\mathrm{CO}_{2}$ laser beam welding of magnesium-based alloys. Weld. J. 1998, 77, 149s-154s.

14. Dilthey, U.; Brandenhurg, A.; Trager, G.; Haferkamp, H.; Niemeyer, M. Laser-and electron beam welding of magnesium alloys. Materialwiss. Werkst. 1999, 30, 682-692. [CrossRef]

15. Weisman, C.; Kearns, W.H. Welding Handbook, 7th ed.; American Welding Society: Miami, FL, USA, 1989; Volume 4, p. 396.

16. Assar, A.; Nami, B.; Arab, N.B.M.; Khoubrou, I. Effect of heat input of TIG repair welding on microstructure and mechanical properties of cast AZ91 magnesium alloy. Weld. World 2021, 65, 1131-1143. [CrossRef]

17. Weng, F.; Liu, Y.; Chew, Y.; Lee, B.Y.; Ng, F.L.; Bi, G. Double-side friction stir welding of thick magnesium alloy: Microstructure and mechanical properties. Sci. Technol. Weld. Join. 2020, 25, 359-368. [CrossRef]

18. Kumar, S.D.; Kumar, S.S. Effect of heat treatment conditions on ballistic behaviour of various zones of friction stir welded magnesium alloy joints. Trans. Nonferrous Met. Soc. China 2021, 31, 156-166. [CrossRef]

19. Cao, X.J.; Jahazi, M.; Immarigeon, J.P.; Wallace, W. A review of laser welding techniques for magnesium alloys. J. Mater. Process. Technol. 2006, 171, 188-204. [CrossRef]

20. Chi, C.T.; Chao, C.G.; Huang, C.A.; Lee, C.H. Investigation of electron beam welding on AZ91D-F extrusive plates. Mater. Sci. Forum 2006, 505, 193-198. [CrossRef]

21. Zhou, W.; Long, T.Z.; Mark, C.K. Hot cracking in tungsten inert gas welding of magnesium alloy AZ91D. Mater. Sci. Technol. 2007, 23, 1294-1299. [CrossRef]

22. Munitz, A.; Cotler, C.; Shaham, H.; Kohn, G. Electron beam welding of magnesium AZ91D plates. Weld. J. 2000, 79, 202s-208s.

23. Nayeb-Hashemi, A.A.; Clark, J.B. Phase Diagrams of Binary Magnesium Alloys; ASM International: Metals Park, OH, USA, 1988.

24. Dissemination of IT for the Promotion of Materials Science (DoITPoMS), University of Cambridge. Available online: https: //www.doitpoms.ac.uk/miclib/phase_diagrams.php?id=70 (accessed on 15 June 2021). 
25. Borland, J.C. Suggested explanation of hot cracking in mild and low alloy steel welds. Brit. Weld. J. 1961, 8, 526-540.

26. Prokhorov, N.N. The technological strength of metals while crystallising during welding. Weld. Prod. 1962, 9, 1-8.

27. Avedesian, M.M. Magnesium and Magnesium Alloys; ASM International: Materials Park, OH, USA, $1999 ;$ pp. 8-9.

28. Zhang, P.L.; Jia, Z.Y.; Yu, Z.S.; Shi, H.C.; Li, S.W.; Wu, D.; Yan, H.; Ye, X.; Chen, J.S.; Wang, F.X.; et al. A review on the effect of laser pulse shaping on the microstructure and hot cracking behavior in the welding of alloys. Opt. Laser Technol. 2021, 140, 107094. [CrossRef] 